\title{
Introduction: North American Natural Gas Markets in Transition
}

\author{
Hillard G. Huntington* \\ Stanford University
}

\begin{abstract}
Over many decades energy markets have seen a variety of new technologies with the potential of replacing existing practices for providing conventional fossil fuels. Unlike synthetic fuels during the 1970s or hydrogen during the 2000s, however, hydraulic fracturing for producing natural gas shale resources has had a dramatic impact because it has been cost effective. This article describes a model-comparison effort organized by Stanford's Energy Modeling Forum and provides a brief overview of the principal findings by individual modeling teams that participated in the study.
\end{abstract}

JEL Classification: Q41, Q55

Keywords: natural gas, shale technology, energy markets

* Executive Director, Energy Modeling Forum, Huang Center, 475 Via Ortega, Stanford University, Stanford, CA 94305-4121, Email: hillh@stanford.edu. Although the views here are solely the author's, he acknowledges the significant contributions of the EMF31 modeling teams and other participants and the valuable financial support during the course of the study from the U.S. Department of Energy, U.S. Environmental Protection Agency and the following organizations: America's Natural Gas Alliance, American Petroleum Institute, Aramco Services, BP America, Central Research Institute of Electric Power Industry (Japan), Chevron, Electric Power Research Institute, Électricité de France, Environment Canada, Exxon Mobil, MITRE Corporation, National Energy Board, Sandia National Laboratory, Sasol North America, Schlumberger, Shell Exploration \& Production, Southern Company, and TransCanada. 


\section{Introduction}

Over many decades energy markets have seen a variety of new technologies with the potential of replacing existing practices for providing conventional fossil fuels. Synthetic fuels during the 1970s, hydrogen during the 2000s and carbon capture and sequestration in today's climate-change constrained times have all captured the fancy of policymakers. And yet, each of these options has not held much promise to date in being major players in the future energy mix because they have not been cost competitive. But since about 2006, hydraulic fracturing combined with horizontal drilling have made substantial in-roads in altering America's energy future by significantly reducing the cost of extracting natural gas from North American shale deposits. Although there are environmental and social challenges associated with its development, the shale revolution has continued to influence American energy markets for more than a decade.

Several important studies have evaluated different modeling and analytical aspects of this key development. International perspectives have been analyzed in Massachusetts Institute of Technology (2011), Paltsev et al (2011), McJeon et al (2014) and Richter and Holz (2015). Prospects for US natural gas exports have been the focus in Ebinger et al (2012), Energy Information Administration (2012), NERA Economic Consulting (2012, 2014) and Medlock (2012). Citi Global Perspectives \& Solutions (2012) and Credit Suisse (2012) have considered the macroeconomic impacts of more plentiful natural gas supplies. Each of these studies has advanced our understanding about how hydraulic fracturing will reshape energy markets.

This article introduces a special issue on evaluating future U.S. energy outlooks resulting from more abundant and less expensive North American natural gas resources. Frequently major energy studies are based upon the results from a single model. The significant feature of this study is that conclusions are drawn from results across multiple models where key input assumptions are similar. The next section 
describes the basic study design adopted by an Energy Modeling Forum (EMF) group organized by Stanford University. ${ }^{1} \quad$ A following section highlights a few results drawn from a comparison of model results that are discussed more extensively in Energy Modeling Forum (2015). The fourth section summarizes the articles by individual modeling teams that appear as separate articles in this special issue, while the final section explains the unique perspectives offered by these articles prepared by the individual modeling teams.

\section{EMF Study Design ${ }^{2}$}

The Energy Modeling Forum formed a working group of about 50 experts and advisors from companies, government agencies and universities to discuss the impacts of shale gas on North American energy markets. This group met four times over October 2013-May2015 period.

Modeling teams from 16 different organizations participated in the full EMF study. All models integrate information on North American energy supply and demand through 2040 or 2050 to provide prices that reach market balances for each of the covered fuels. The models adopt either an economic equilibrium, engineering process, or some blended or hybrid approach for representing energy supply, demand and prices in the United States.

The EMF working group considered 9 scenarios with some key exogenous information standardized across models. Results from each of the last 8 scenarios can be compared to estimates from the first case (called the "Reference" scenario) to understand the responses of each framework to changed conditions. Conditions that were altered in these other 8 cases include: (1) the cost and availability of U.S. natural gas shale supplies, (2) federal emissions policy for the electric generation sector, (3) the Asian demand for natural gas exports, (4) Asian contracts for setting the delivered natural gas prices,

\footnotetext{
${ }^{1}$ This effort is the second, two-year EMF study that builds upon the previous study summarized in the Energy Modeling Forum (2013).

${ }^{2}$ Please see Energy Modeling Forum (2015) for additional discussion about the study design, scenarios and modeling approaches.
} 
and (5) the cost and availability of Russian natural gas supplies. The appendix in Energy Modeling Forum (2015) contains the complete study design that specifies the detailed assumptions used in each case.

The study specified a reference case patterned after the 2014 Annual Energy Outlook reference case released by the U.S. Energy Information Administration, available at http://www.eia.gov/oiaf/aeo/ tablebrowser/. The study used this scenario as a control case for comparing other scenarios rather than as the preferred outlook prepared by each modeling team. Key exogenous assumptions for the 20122040 period in this case include world crude oil prices (Brent) rising by $0.8 \%$ per year to reach $\$ 141$ per barrel (2012 U.S. dollars) by 2040 and the U.S. economy growing by $2.4 \%$ per year. In addition, the U.S. government does not impose any new energy or environmental regulatory policies after 2013 . The single exception with regard to regulatory policy is inclusion of the proposed New Source Performance Standards (NSPS) for carbon dioxide (CO2), which effectively prohibits new coal plants unless they have carbon capture and sequestration (CCS). These factors are the principal demand drivers used by the modeling teams and are combined with resource supply conditions represented in each framework to produce market outcomes such as natural gas prices, production, consumption and export/import balances.

\section{Summary of the Model Comparison}

Energy Modeling Forum (2015) documents the very large variations in estimated natural gas production, consumption, exports and prices across models, even within any one scenario. Poorly understood resource basins account for only some of this imprecision. An additional significant source for this uncertainty is the trend foreseen for domestic natural gas use in the U.S. economy. An important example is the country's plans for promoting cleaner electric power through controls on that sector's carbon dioxide emissions. The study evaluates one of many ways that the Administration's Clean Power 
Plan $(\mathrm{CPP})^{3}$ could be implemented, although court reviews continue to hold back its implementation. Another key demand issue will be expansions in sectors like the chemical industry. Overseas conditions will also shape the future growth of the US export market and its impact on domestic natural gas prices.

Figure 1 shows the major changes in 2040 energy market conditions due to the high-shale conditions. The chart standardizes each model's response by displaying the percentage impact for each variable associated with a $10 \%$ reduction in Henry Hub wellhead prices for natural gas. These standardized effects are more revealing about the model outcomes than the original impacts themselves. The vertical bar for each impact listed on the horizontal axis displays the high and low end of the model estimates. The small square indicates the average 2040 impact for all models.

Adjusted for inflation, coal mine-mouth prices shown at the far left decline modestly below reference levels in most models as natural gas replaces coal use. ${ }^{4}$ The second bar indicates that lower natural gas prices reduce electric generation costs and retail prices for all customers by $3.7 \%$ below reference levels by 2040 on average. Electricity costs and prices decline below reference levels, but by considerably less than natural gas prices (10\%).

Competition from natural gas (the third bar) tends to reduce primarily the consumption of coal (the fourth bar) with much smaller impacts on liquids, nuclear or renewables. On net, less expensive natural gas increases total primary energy use modestly. Real GDP does not change appreciably, reflecting natural gas's small share in the total economy (about 1 percent). Carbon dioxide emissions also do not change much with more abundant natural gas. Although natural gas displaces carbon-intensive coal, it also discourages investment in clean-fuel sources like nuclear and renewables. Additionally, lower natural gas prices reduce energy efficiency improvements and stimulate some increases in economic

\footnotetext{
${ }^{3}$ U.S. Environmental Protection Agency (2016).

${ }^{4}$ Unless indicated otherwise, percent increases or decreases in this section refer to impacts or changes above or below reference levels for the same year rather than changes over time.
} 
activity, both of which may cause U.S. carbon dioxide emissions to increase. The study did not address which way global emissions would move. ${ }^{5}$ On the one hand, an increase in US economic activity could come at the expense of activity in other regions which may result in a net increase or decrease in global emissions depending upon the relative regional carbon dioxide intensities. On the other hand, an increase in US economic activity could cause an increase in global activity outside the US leading to more emissions.

These conditions also influence the electric sector significantly. On average, electric use of natural gas increases by $8.1 \%$ (compared to $5.3 \%$ economywide). Reduced electricity prices cause total electricity sales to increase by a relatively modest $1.0 \%$ compared to the expansion in total natural gas sales (5.0\%). The faster expansion in direct natural gas sales than in electricity sales reflects the larger decline in the natural gas price than in its electricity counterpart, as discussed above.

\section{Contributions from the Modeling Teams}

This section provides a broad overview of the individual analysis provided by each of nine modeling team on topics of their own choosing. There is a broad coverage of topics but many focus upon the prospects for U.S. exports or the implications of power-sector carbon dioxide targets for natural gas and competing fuels.

Yeh and her colleagues compare three very different structural models focusing upon the global consequences of the U.S. shale gas boom. The partial equilibrium model of the world natural gas market suggests that the U.S. shale gas boom raises U.S. production, reduces global natural gas prices and displaces natural gas production in non-U.S. regions. A general equilibrium framework adds to these results additional GDP effects because of lower global natural gas prices that increase demand and hence enable production of non-U.S. regions to recover in the long run. A third game-theoretic model

\footnotetext{
${ }^{5}$ See McJeon et al (2014) for a comparison of global emissions due to increased world natural gas availability.
} 
combines flexible technology and fuel substitutions that tend to moderate impacts of supply/demand shocks. As natural gas supplies displace coal use in the power sector in some regions in this third framework, coal producers find it economic to shift their supplies to other markets and hence reduce the penetration of natural gas. U.S. exports vary widely across the three models even when they standardize on some key input assumptions.

Applying a world computable general equilibrium framework, Arora, Cai and Jones evaluate the national and international impacts of Chinese coal-to-gas switching in the electric power sector following one of the EMF 31 scenarios. Assumptions about electricity growth rates from renewables are critical in explaining alternative pathways for coal-to-gas switching in China. When renewables supplement natural gas generation in displacing coal, Chinese and global economic activity suffer less.

After considering several important uncertainties about U.S. natural gas resources, market conditions, changing U.S. environmental regulations, and possible changes in geopolitical conditions, Bernstein and his colleagues show that U.S. exports depend upon how U.S. prices change relative to price changes in other regions of the world. They illustrate these effects through a world partial equilibrium model of the world natural gas market that allows inter-regional gas trade through liquefied natural gas (LNG) facilities and pipelines. Although U.S. LNG exports are uncompetitive in the Reference case, these sources may become more competitive under different conditions: when U.S. natural gas resources are plentiful, Asian demand is significantly higher, Russian supplies are more costly or curtailed, or oil-indexed pricing in Asia is more persistent. They conclude that limiting U.S. LNG exports may be premature and that policymakers should leave these decisions to the market to determine the levels and destination of exports.

The U.S. Environmental Protection Agency has proposed the Clean Power Plan (CPP) regulating carbon dioxide emissions from existing power plants under Section 111d of the Clean Air Act. In the first of two papers exploring multiple dimensions of the plan, Wright and Kanundia explore the implications 
for electric generation fuel choice and natural gas markets based upon results from a detailed, multipleregion, technology-based model of the U.S. electric power system. They find that the achieved levels of energy efficiency (EE) play a critical role. The absence of EE causes the CPP to raise gas production and prices by stimulating a shift from coal to gas. By contrast, gas production and price fall below no-policy levels by the mid-2020s when the EE levels projected by EPA are achieved as part of state compliance approaches.

In a second paper on the CPP, Ross and Murray employ an economy/electricity model to examine the consequences of a range of flexible policy mechanisms including interstate trade obligations and mass-based targets (rather than rate-based ones). They conclude that the CPP tends to reinforce the displacement of coal by natural gas within electricity generation. They also find that a ratebased CPP target contributes to additional gas use in the early years than a mass-based approach but the effect disappears over time with the construction of new more-efficient gas units. Their analysis also portends more intense future regional variation and dislocations in fuel markets, especially over the next five years.

Although a cleaner burning fuel than coal that emits lower carbon dioxide emissions, natural gas releases methane upstream in the extraction and production of this resource. Lenox and Kaplan use a regional MARKAL linear optimization model to evaluate both carbon and methane emissions profiles for the U.S. energy system when carbon dioxide reduction targets are specified for the power sector. They find that these policies tend to reduce the system carbon dioxide emissions in most scenarios, but that the contribution of upstream methane emissions from natural gas extraction and production, if beyond a certain percent of total natural gas extracted, can lead to an increase in total carbon dioxide equivalent emissions (including methane) when natural gas prices remain low and natural gas is more abundant. 
Healey, Jaccard and Peters focus upon how an emissions-intensity standard (metric tons of CO2 per MWh of electricity) for the U.S. power sector influences U.S. final energy demand more broadly across all sectors, including manufacturing, residential, commercial, and transportation. Basing their results on a hybrid energy-economy simulation model (CIMS), they estimate a relatively small effect on aggregate emissions even though some sub-sectors have relatively large changes. Their results underscore the need for emissions-reduction policies in other sectors rather than adopting a target for the power sector alone if one wants deep emissions cuts.

Hanson and his colleagues emphasize various electric power system constraints that may pose problems when displacing coal generators with natural gas or intermittent renewable units. This displacement may require more frequent stopping and starting of existing coal units (called cycling) leading to unit damage and closure. Over a representative week, many coal-fired powerplants may experience operating cycles where the units need to be cooled down and re-heated. Under these conditions simple levelized cost of electricity (LCOE) may not be an appropriate investment criterion for gas-fired NGCC units. They demonstrate these considerations by modeling the interactions between electricity production and the natural gas market and applying it to a stringent technology performance standard as in the EMF31 study.

Cole and his colleagues highlight the value of integrating two highly spatially resolved models for the natural gas market and the U.S. electricity sector. The natural gas model provides natural gas prices paid by generators for the electric utility model, while the latter estimates utility natural gas demand for the natural gas model. The two model converge with similar national results to those when the models are operated independently, but the regional results are quite different. Combining these two models, therefore, may be particularly important for electric sector planners considering their responses to recent electric sector policy changes (e.g., the Clean Power Plan) that operate at the state level. 


\section{Summary}

The nine articles in this special issue provide a unique opportunity to expand the study beyond only the scenarios and results that all models could report in the formal model-comparison exercise. Focusing upon the unique characteristics of each modeling framework allows the working group to explore a wider set of issues that are important for understanding the transitions unfolding in the natural gas market. 


\section{References}

Citi Global Perspectives \& Solutions (2012), “Energy 2020: North America, the New Middle East?" March.

Credit Suisse (2012), "The Shale Revolution," Securities Research \& Analytics, 13 December 2012. http://www.credit-suisse.com/researchandanalytics

Ebinger, Charles, Kevin Massy and Govinda Avasarala (2012), "Liquid Markets: Assessing the Case for U.S. Exports of Liquefied Natural Gas," Policy Brief 12-01, Brookings Institution, Washington, DC, May.

Energy Information A (2012), "Effect of Increased Natural Gas Exports on Domestic Energy Markets," U.S. Energy Information Administration, January 2012.

Energy Modeling Forum (2013), Changing the Game? Emissions and Market Implications of New Natural Gas Supplies, EMF 26 Working Group Report, Stanford University, Stanford, CA.

Energy Modeling Forum (2015), North American Natural Gas Markets in Transition, EMF 31 Working Group Report, Stanford University, Stanford, CA.

McJeon HC, JA Edmonds, N Bauer, LE Clarke, B Fisher, BP Flannery, J Hilaire, V Krey, G Marangoni, R Mi, K Riahi, HH Rogner, and M Tavoni (2014). "Limited Impact on Decadal-Scale Climate Change from Increased Use of Natural Gas." Nature 514(7523):482-485.

Massachusetts Institute of Technology (2011). "The Future of Natural Gas: An Interdisciplinary MIT Study," Report. Massachusetts Institute of Technology Energy Initiative, Cambridge, MA.

Medlock, Kenneth B. (2012), "US LNG Exports: Truth and Consequence," Baker Institute for Public Policy, Rice University, Discussion Paper.

NERA Economic Consulting (2012), "Macroeconomic Impacts of LNG Exports from the United States," Washington, DC.

NERA Economic Consulting (2014), "Updated Macroeconomic Impacts of LNG Exports from the United States," Washington, DC.

Paltsev, Sergey, Henry D. Jacoby, John M. Reilly, Qudsia J. Ejaz, Jennifer Morris, Francis O'Sullivan, Sebastian Rausch, Niven Winchester, and Oghenerume Kragha (2011). "The Future of U.S. Natural Gas Production, Use, and Trade”, Energy Policy, Volume 39, Issue 9, September, Pages 5309-5321.

Richter, Philipp M. and Franziska Holz (2015). "All Quiet on the Eastern Front? Disruption Scenarios of Russian Natural Gas Supply to Europe," Energy Policy, 80: 177-189 (May), ISSN0301-4215, http://dx.doi.org/10.1016/j.enpol.2015.01.024.

U.S. Environmental Protection Agency (2016), Clean Power Plan Proposed Rule, Available at http://www2.epa.gov/carbon-pollution-standards/clean-power-plan-proposed-rule. 
Figure 1. Impacts for 10\% Reduction in Wellhead Natural Gas Price in 2040

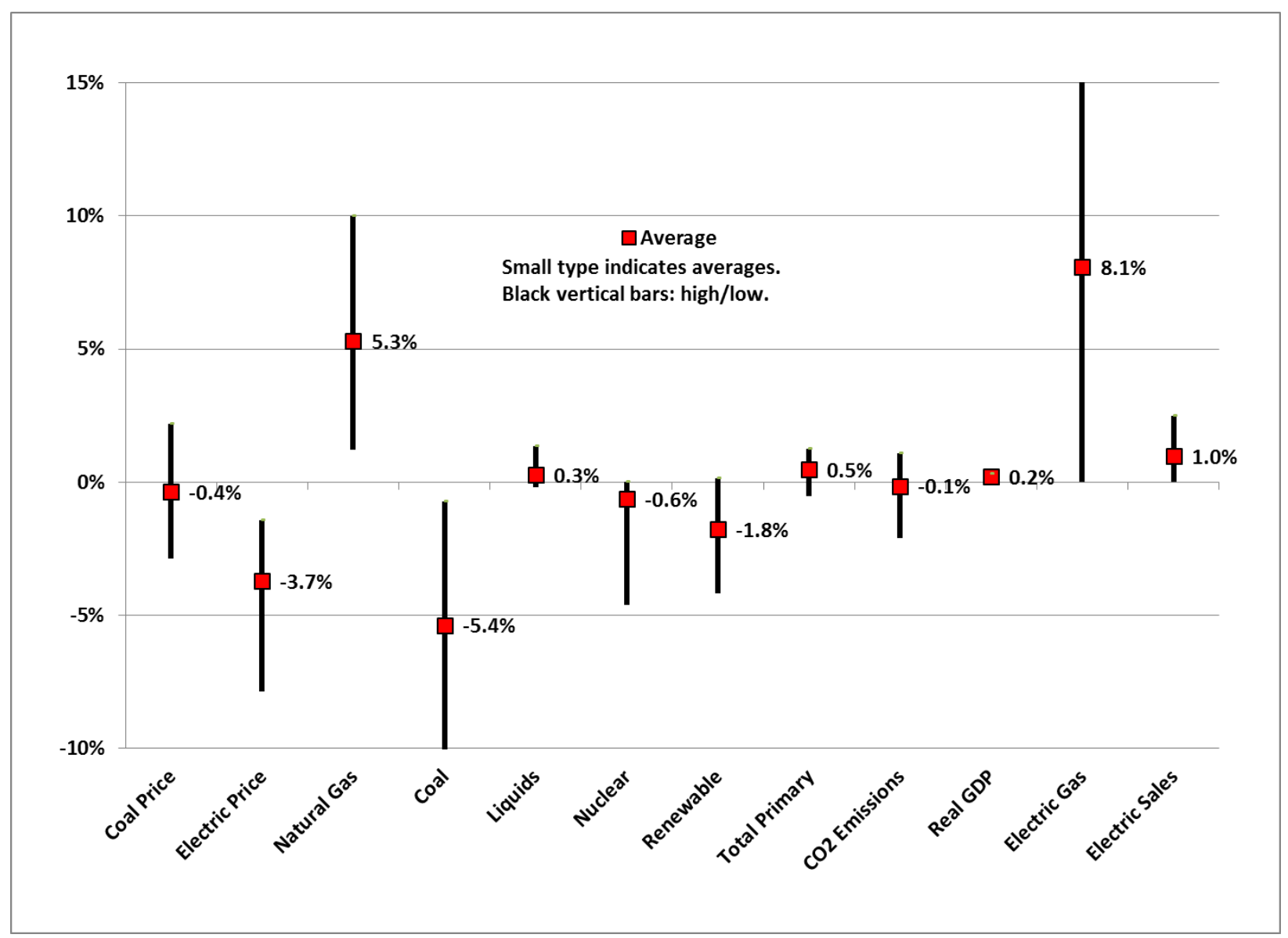

